\title{
SOIL FEEDBACK OF EXOTIC SAVANNA GRASS RELATES TO PATHOGEN ABSENCE AND MYCORRHIZAL SELECTIVITY
}

\author{
W. H. van der Putten, ${ }^{1,2,6}$ G. A. Kowalchuk, ${ }^{1,3}$ E. P. Brinkman, ${ }^{1}$ G. T. A. Doodeman, ${ }^{1}$ R. M. van der Kaaij, ${ }^{1,4}$ \\ A. F. D. Kamp, ${ }^{1}$ F. B. J. Menting, ${ }^{1}$ and E. M. Veenendaal ${ }^{4,5}$ \\ ${ }^{1}$ Netherlands Institute of Ecology, Centre for Terrestrial Ecology (NIOO-KNAW), P.O. Box 40, 6666 ZG Heteren, The Netherlands \\ ${ }^{2}$ Laboratory of Nematology, Wageningen University, P.O. Box 8123, 6700 ES Wageningen, The Netherlands \\ ${ }^{3}$ Free University of Amsterdam, Institute of Ecological Sciences, De Boelelaan 1085, 1081 HV Amsterdam, The Netherlands \\ ${ }^{4}$ Harry Oppenheimer Okavango Research Centre, Private Bag 285, Maun, Botswana \\ ${ }^{5}$ Nature Conservation and Plant Ecology Group, Wageningen University, Bornsesteeg 69, 6708 PD Wageningen, The Netherlands
}

Abstract. Enemy release of exotic plants from soil pathogens has been tested by examining plant-soil feedback effects in repetitive growth cycles. However, positive soil feedback may also be due to enhanced benefit from the local arbuscular mycorrhizal fungi (AMF). Few studies actually have tested pathogen effects, and none of them did so in arid savannas. In the Kalahari savanna in Botswana, we compared the soil feedback of the exotic grass Cenchrus biflorus with that of two dominant native grasses, Eragrostis lehmanniana and Aristida meridionalis. The exotic grass had neutral to positive soil feedback, whereas both native grasses showed neutral to negative feedback effects.

Isolation and testing of root-inhabiting fungi of E. lehmanniana yielded two host-specific pathogens that did not influence the exotic $C$. biflorus or the other native grass, A. meridionalis. None of the grasses was affected by the fungi that were isolated from the roots of the exotic $C$. biflorus. We isolated and compared the AMF community of the native and exotic grasses by polymerase chain reaction-denaturing gradient gel elecrophoresis (PCR-DGGE), targeting AMF 18S rRNA. We used roots from monospecific field stands and from plants grown in pots with mixtures of soils from the monospecific field stands. Three-quarters of the root samples of the exotic grass had two nearly identical sequences, showing 99\% similarity with Glomus versiforme. The two native grasses were also associated with distinct bands, but each of these bands occurred in only a fraction of the root samples. The native grasses contained a higher diversity of AMF bands than the exotic grass. Canonical correspondence analyses of the AMF band patterns revealed almost as much difference between the native and exotic grasses as between the native grasses.

In conclusion, our results support the hypothesis that release from soil-borne enemies may facilitate local abundance of exotic plants, and we provide the first evidence that these processes may occur in arid savanna ecosystems. Pathogenicity tests implicated the involvement of soil pathogens in the soil feedback responses, and further studies should reveal the functional consequences of the observed high infection with a low diversity of AMF in the roots of exotic plants.

Key words: arbuscular mycorrhizal fungi; arid savanna; Aristida meridionalis; Botswana; Cenchrus biflorus; enemy release; Eragrostis lehmanniana; invasive species; plant-soil feedback; soil pathogens.

\section{INTRODUCTION}

A prominent hypothesis to explain high local abundance of exotic plant species assumes release from their natural enemies (Williamson 1996, Keane and Crawley 2002). The majority of enemy release research has focused on aboveground interactions between plants, herbivores, and pathogens (e.g., Jobin et al. 1996, Memmott et al. 2000, Müller-Schärer et al. 2004). Some invasive plants appear to experience release of soil-borne enemies in the new range (Klironomos 2002, Reinhart et al. 2003, Wardle et al. 2004, Agrawal et al. 2005).

Manuscript received 21 June 2006; revised 3 September 2006; accepted 6 September 2006. Corresponding Editor: J. N. Klironomos.

${ }^{6}$ E-mail: w.vanderputten@nioo.knaw.nl
However, other studies are showing biotic resistance from the local soil community against the exotics (Beckstead and Parker 2003, Knevel et al. 2004, Parker and Hay 2005, Parker et al. 2006). Here, we studied plant-soil feedback of an invasive and two native grasses in the Kalahari savanna. Plant-soil feedback studies examine how plants influence the community of soil organisms and how these changes affect the performance of individual plants and the composition of plant communities. Thus far, plant-soil feedback studies have focused mainly on temperate grassland and forest ecosystems (Van der Putten 2003), while extreme environments, such as arid ecosystems, have been understudied.

A common practice to test plant responses to soil organisms is to expose plants to soil conditioned by their 
own or by other species, which provides a sum of total soil feedback effects (Bever et al. 1997). Any feedback effect between a plant and its soil community is a net effect of pathogens, symbiotic mutualists, and decomposer organisms so that a neutral or positive soil feedback of an exotic plant may be due to release from enemies or enhanced benefit from symbiotic mutualists (Reinhart and Callaway 2006). Exotic plants have been proposed to benefit disproportionately from symbiotic mutualists (Richardson et al. 2000), providing them with additional advantage over native species. However, the lack of detail about the positive vs. negative components complicates the testing of the release of exotic plants from natural enemies (Colautti et al. 2004), or their facilitative effects toward the exotic plants (Reinhart and Callaway 2004).

We performed a two-stage plant-soil feedback experiment with two native grasses and one exotic grass that co-occur in the Kalahari savanna, Botswana, southern Africa. The native grasses chosen were Eragrostis lehmanniana and Aristida meridionalis, both perennial species that can locally dominate the Kalahari plant community. As an exotic plant species, we used Cenchrus biflorus, a grass that has been accidentally introduced into southern Africa (Bond et al. 2002) and is now a major pest in disturbed sites, such as road verges and around cattle-watering points. The feedback experiment started with a soil conditioning phase, followed by a full reciprocal feedback test, with each plant species grown in soil conditioned by its own (conspecific) species, vs. soil conditioned by other (heterospecific) species. Then, in order to test the effects of potential soil pathogens, the fungi were isolated from the plant roots, cultured, identified, and used in pathogenicity trials to test their effects on plant performance. In order to study the infection of the native and exotic plant species by the arbuscular mycorrhizal community, field samples from adjacent plant populations were examined by specific molecular community profiling by polymerase chain reaction-denaturing gradient gel elecrophoresis (PCRDGGE), targeting the 18S rRNA gene. Finally, in order to analyze selective effects in a multispecies community of arbuscular mycorrhizal fungi (AMF) we grew the three plant species in mixed soil collected from the three field stands, and analyzed the molecular AMF community profile in the roots.

In the feedback experiment, we tested the hypothesis that soil biota would have a neutral to positive effect on the exotic grass (Klironomos 2002), while we assumed that the effects would be neutral to negative on the native plant species. In pathogenicity trials, we tested the hypothesis that native plants may have specific soil pathogens, but exotic plants may not (Mitchell and Power 2003). We also analyzed if exotic plants might accumulate pathogens of the native species (Eppinga et al. 2006). The molecular AMF identification was applied to test the hypothesis that exotic plant species can have access to local mutualistic symbionts (Richardson et al.
2000), and that exotic plant species can have higher levels of AMF infection than native plant species (Batten et al. 2006). Previous studies have suggested that AMF may directly (Marler et al. 1999) or indirectly (Callaway et al. 2004, Mummey et al. 2005) enhance performance of exotic plants in interspecific interactions. We discuss how local abundance of exotic plants may be due to enemy release (Keane and Crawley 2002) or to benefits from local symbionts (Richardson et al. 2000).

\section{Materials And Methods}

\section{Plant species and collection of seeds and soil}

Cenchrus biflorus Roxb. is an annual or short-lived perennial grass that was accidentally introduced in the Kalahari savanna of Botswana (nomenclature follows Gibbs Russel et al. 1991, Bond et al. 2002). Cenchrus biflorus produces seeds that are enclosed in clusters surrounded by many sharp spines, which get attached to the fur of animals, and to clothing and vehicles, allowing easy dispersal (Anonymous 1996). Cenchrus biflorus predominantly occurs in cattle paddocks and other moderately disturbed sites, such as cattle tracks, around water boreholes, and road verges. Eragrostis lehmanniana Nees (Lehman's lovegrass) is a wind-dispersed perennial bunchgrass (Cox et al. 1990) that is indigenous to southern Africa and has spread to East Africa, India, and America (Anable et al. 1992). The plant can reach up to $0.6 \mathrm{~m}$. Within this range, it is common in semidesert grasslands and sandy (loam) soils. Aristida meridionalis Henr. (giant stick grass) is a tall perennial bunchgrass that can reach up to $2 \mathrm{~m}$. It is indigenous to southern Africa and widespread on sandy soils.

Seeds and rhizosphere soil of C. biflorus, E. lehmanniana, and A. meridionalis were collected from Ghanzi, Botswana, which is representative of invaded Kalahari savanna grassland communities. This material was shipped to The Netherlands, to test the soil feedback in controlled conditions. In order to start from similar abiotic material, the soil samples used for the feedback experiment were inoculated into a sterilized $(25 \mathrm{kGy}$ [kilogray] $\gamma$-irradiation [Van der Putten et al. 1993]) sandy soil mixture that contained one part river sand of Pleistocene origin and six parts sandy soil of a former glacial deposition that had a texture similar to that of the Kalahari sand. The sterilized soil was inoculated with 3\% (mass/mass) soil (Van der Putten et al. 1988) collected from the root zone of the three plant species.

\section{Soil conditioning and feedback experiments}

Conditioning and feedback growth experiments (lasting three and two months, respectively) were carried out with C. biflorus, E. lehmanniana, and A. meridionalis. Seeds were germinated under an $8 / 16$ hours dark/light regime at $15^{\circ} / 25^{\circ} \mathrm{C}$. Ten individuals of each plant species were grown in five 20-L containers with sterilized soil and in five such containers with a sterilized soil inoculated with $3 \%$ (mass/mass) of conspecific nonsterile rhizosphere inoculum. There were 3 (plant species) $\times 2$ 
(with and without inoculum) $\times 5$ (replicates) $=30$ containers involved in the conditioning phase.

Plant shoots were harvested, dried to constant mass at $70^{\circ} \mathrm{C}$, and weighed in order to determine if the soil inocula had any effect on aboveground plant biomass, which is the most important parameter indicative of plant abundance. A subsample of randomly collected roots was collected and stored at $4^{\circ} \mathrm{C}$ to be used for isolating potentially pathogenic root-associated fungi. The soil with the remaining roots was homogenized while removing belowground rhizomes and shoots and placed in 1.5 -L pots to perform the feedback experiment, where we tested the consequences of plant-specific enhancement of soil organisms, originating from the $3 \%$ inoculum in cross combinations of plants and soils. We grew every plant in its own (conspecific) soil, as well as in (heterospecific) soil from the two other plant species, with and without inoculum. This feedback experiment involved 3 plant species $\times 3$ soil conditionings (one conspecific and two heterospecific) $\times 2$ soil treatments (with and without inoculum in the conditioning phase) $\times$ 5 replicates $=90$ pots. In addition, we included pots with each plant species on its conspecific soil sterilized by $\gamma$ irradiation $(25 \mathrm{kGy})$ in order to test the consequence of excluding soil organisms. This addition included 3 plant species $\times 5$ replicates $=15$ pots. In both conditioning and feedback experiments, Hoagland nutrient solution was supplied in order to overcome differences in nutrient availability (Van der Putten et al. 1988).

\section{Fungal pathogenicity tests}

After the conditioning stage, for each root sample, 15 root pieces of $1 \mathrm{~cm}$ were surface-sterilized for 15 seconds in a $1 \%$ sodium hypochlorite solution, washed four times in sterile demineralized water, and distributed over five Petri dishes with malt extract agar. The agar was prepared with $20 \mathrm{~g}$ malt extract (Oxoid Limited, Basingstoke, UK), $3 \mathrm{~g}$ peptone (Oxoid), $15 \mathrm{~g}$ agar (Merck and Company, Whitehouse, New Jersey, USA), 2.5 g ox-bile, and $50 \mathrm{mg} / \mathrm{kg}$ oxytetracycline. Directly after their detection, samples from all developing fungal colonies were taken to establish pure cultures on solid PDA medium (potato dextrose agar; Oxoid). After two weeks, the spores of sporulating fungi were washed from the culture with sterile demineralized water, counted using a Fuchs-Rosenthal (Brand, Wertheim, Germany) counting chamber, and used for pathogenicity tests. If fungi did not sporulate, mycelial inocula on PDA discs $5 \mathrm{~mm}$ in diameter were cut out to be added to the test plants in the pathogenicity tests. Fungi were labelled according to their plant host and isolate number (for C. biflorus: Cb1, $\mathrm{Cb} 2$, etc.) and submitted to the Central Bureau for Fungal Collections, Utrecht, The Netherlands (CBSKNAW) for identification.

Seeds from $C$. biflorus, E. lehmanniana, and $A$. meridionalis were surface sterilized (5-15 minutes, $1 \%$ hypochlorite [mass/volume]) and tested for sterility on TSB (tryptone soya broth) for presence of bacteria, and on PDA for presence of fungi prior to germination. Beakers of $250 \mathrm{~mL}$ were filled with $150 \mathrm{~g}$ of sterilized dry soil and $7.5 \mathrm{~mL}$ full strength Hoagland nutrient solution was added for plant nutrition, and sterilized demineralized water was added to obtain 5\% soil moisture (mass/mass). In a sterile laminar flow cabinet environment, two-week-old seedlings were transferred from the Petri dishes to the beakers, which were covered with sterile Parafilm (American Can Company, New Orleans, Louisiana, USA). The beakers were placed in a growth chamber in a completely randomized design (rotated twice a week to avoid position effects) with an 8/16 hours dark/light regime at $18^{\circ} / 21^{\circ} \mathrm{C}$ and a day length of 16 hours at $200 \mu \mathrm{mol} \cdot \mathrm{m}^{-2} \cdot \mathrm{h}^{-1}$.

One week after planting, fungal inoculum was added to the plants at a density of $10^{4}$ spores per plant, or three patches of mycelium per plant for the nonsporulating fungi. Another $2 \mathrm{~mL}$ of sterile demineralized water was added, so that the soil water content became $6.3 \%$ (mass/mass) to enable plant growth without having to add water during the experimental period. Pathogenicity of the fungi was determined by measuring necrosis (browning) of the four oldest leaves (Eragrostis) or of all three leaves (Aristida, Cenchrus). The necrosis estimates enabled us to nondestructively determine growth retardation. The pathogenicity trials were running for 24-38 days, after which roots were surface sterilized (as previously described) and placed on PDA Petri dishes to confirm the presence of the inoculated fungi inside the roots. First, two trials were carried out with $E$. lehmanniana, which showed a trend of growth reduction in the conditioning phase, and then one trial with a subset of fungi to assess their effects on C. biflorus and A. meridionalis.

\section{In-root molecular characterization of arbuscular mycorrhizal fungi}

In the field at Ghanzi, soil and root material was collected from seven monospecific stands of $C$. biflorus, A. meridionalis, and E. lehmanniana. At the Okavango Research Station at Maun, Botswana, the soil samples collected under all three plant species were homogenized using equal volumes and separated into 10 replicate samples (as we were not interested in natural variation in the field, but in the selectivity of plant-AMF associations). The roots were sifted out, chopped and re-entered into the soil as inoculum source. We planted $301.5-\mathrm{L}$ pots with two seedlings of either $C$. biflorus, or $A$. meridionalis, or E. lehmanniana. For 33 days, the plants were grown outdoors in a shade house allowing 50\% sunlight to enter. Tap water was supplied regularly to avoid desiccation. At harvest, roots were washed from the soil and prior to DNA extraction, root surface fungi were removed by sonifying roots two times for five minutes each, first in $10 \mathrm{mmol} / \mathrm{L}$ sodium pyrophosphate and then in distilled water (De Rooij-van der Goes 1995). The same procedure was applied to the roots from the field samples. 
DGGE-based molecular identification techniques (Kowalchuk et al. 1997) were used to assess the AMF taxa present in the roots of the native and exotic savanna grasses. For root samples collected from the field, DNA was isolated using the PUREGENE DNA isolation kit according to a modified protocol (Gentra Systems, Research Triangle Park, North Carolina, USA). The isolation of DNA from plant roots grown on the mixed soil was performed using the UltraClean Soil DNA Isolation Kit (MoBio Laboratories, Carlsbad, California, USA). Prior to DNA isolation, root material for DNA was first dried for three hours at $65^{\circ} \mathrm{C}$ and subsequently crushed under liquid $\mathrm{N}_{2}$. Then, $0.25 \mathrm{~g}$ of pulverized root material was used in the DNA extraction, according to the manufacturer's standard protocol, except that beadbeating $(2 \times 30$ seconds $)$ was substituted for vortexing. Further details are supplied in Appendix A.

Specific PCR amplification of mycorrhizal 18S ribosomal DNA fragments for DGGE analysis was achieved using the primers NS31GC and AM1 (Helgason et al. 1998). NS31 is described as a universal fungal primer (Simon et al. 1992), with the GC designation indicating the inclusion of the GC-clamp of Kowalchuk et al. (1997) to improve mobility properties for DGGE. The AM1 primer is generally described as specific to the AMF orders of the Glomerales and Diversisporales, but not the Archaeosporales and Paraglomerales. Further details on PCR-amplification are supplied in Appendix A. Approximately $0.5 \mu \mathrm{g}$ of PCR product was used for DGGE analysis, using a modification of the method of Muyzer et al. (1998) as described in Appendix B.

\section{Sequence analysis of DGGE bands and partial $18 S$ rDNA sequences from spores}

The two DGGE bands that occurred in the majority of the $C$. biflorus samples were excised from the acrylamide gels, and DNA eluded as described in the previous section (Kowalchuk et al. 1997). Eluted DNA $(5 \mu \mathrm{L})$ was used for PCR amplification, and products again analyzed by DGGE to confirm purity. Products then were purified with the QiaQuick PCR purification kit (Qiagen, Hilden, Germany) with a final elution volume of $30 \mu \mathrm{L}$. Purified PCR product (200 ng) was used for ligation into a pGEM-T vector (Promega, Madison, Wisconsin, USA) for transformation of Epicurian Coli XL2-Blue supercompetent cells (Stratagene, La Jolla, California, USA) according to the manufacturer's recommended protocol. The presence of inserts of the expected size was confirmed by colony PCR using the vector-targeting primers SP6 and T7 (Promega), as well as the primers NS31 (without GC clamp) and AM1 (Helgason et al. 1998). For the SP6/T7 primer pair, PCR was treated in $25-\mu \mathrm{L}$ samples using the following thermocycling program: 30 rounds of $94^{\circ} \mathrm{C}(30$ seconds), $55^{\circ} \mathrm{C}$ (60 seconds), and $72^{\circ} \mathrm{C}$ (120 seconds), with two units of Tbr polymerase according to the manufacturer's recommended buffer conditions (Finnzymes, Ipoo, Finland). Reactions using the NS31 / AM1 primer pair used the same conditions as described above for amplification of AMF 18S rRNA gene fragments from experimentally grown plants in this study (see Materials and Methods: In-root molecular characterization ...). Five recombinant colonies per ligation were analyzed, with two of each containing the correct size and specificity chosen for sequence analysis, using the primers SP6 and T7. Similarity comparisons of partial $18 \mathrm{~S}$ rDNA sequences were performed using the BLAST 2.0 algorithm (Altschul et al. 1997). The two sequences have been submitted to the European Molecular Biology Laboratory (EMBL) sequence database (available online $)^{7}$ under accession numbers AM279398 and AM279399.

\section{Data analysis}

For the conditioning stage, the effect of adding root zone inoculum on plant biomass was analyzed with $t$ tests. Feedback of each plant species in nonsterilized vs. sterilized soil was calculated as ([biomass in nonsterilized - sterilized soil]/sterilized soil). The effect of adding root zone soil in the first stage on plant biomass was analyzed by one-way ANOVA or, when no homogeneity of variances could be achieved, by Kruskal-Wallis nonparametric test. Differences from zero of the feedback effects were calculated by $t$ tests. The feedback of Cenchrus, Eragrostis, and Aristida in soil of their own (conspecific) soil and in soil of other (heterospecific) species conditioned with and without 3\% rhizosphere inoculum was calculated as ([biomass in inoculated noninoculated]/noninoculated). Statistical analysis of the feedback in nonsterilized and sterilized conspecific soils was the same as for the conspecific and heterospecific soils. Necrosis data of the fungal pathogenicity tests were analyzed by means of ANOVA with repeated measures, using the program STATISTICA 7 (STATSOFT, Tulsa, Oklahoma, USA). If necessary, data were square-root or square-root(square-root) transformed to obtain homogeneity of variances. Treatments were compared by Tukey's HSD posthoc tests with $P<$ 0.05. In this case, where transformed data have been used for statistical analysis, graphs present the backtransformed data.

DGGE images were examined within the ImageMaster Elite program (version 4.20; Amersham Pharmacia Biotech, GE Healthcare UK Limited, Little Chalfont, UK), using a rolling circle background subtraction prior to band detection $(r=50)$. To facilitate lane alignments across gels, DGGE lanes were standardized in reference to marker lanes containing a mixture of $18 \mathrm{~S}$ rDNA fragments from pure isolates of Glomus clarum, Scutellospora gregaria, and Gigaspora albida. Normalized banding patterns were exported to the ImageMaster 1D Database program (version 3.0; Amersham Pharmacia Biotech), where matching of

\footnotetext{
${ }^{7}\langle$ www.ebi.ac.uk/embl/〉
} 


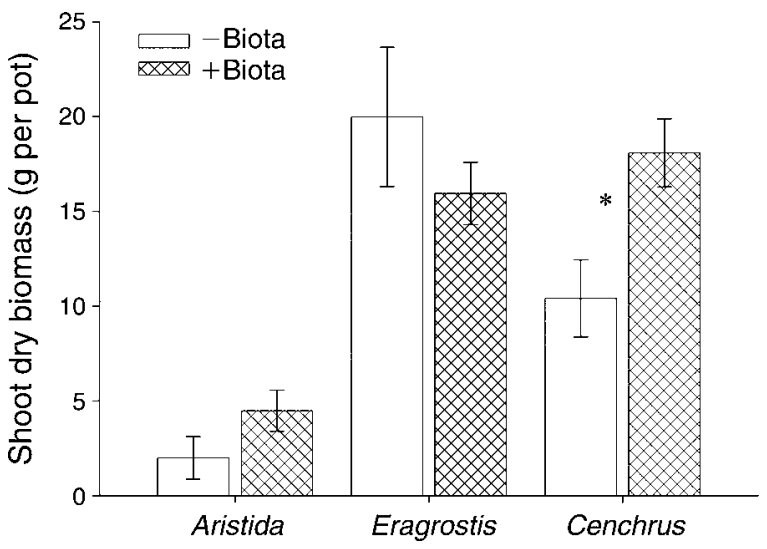

FIG. 1. Conditioning experiment. Total aboveground dry mass of Aristida meridionalis, Cenchrus biflorus, and Eragrostis lehmanniana in sterilized soil with and without $3 \%$ soil from their own root zone added. The asterisk $(*)$ indicates a significant difference $(P<0.05)$ between soils with and without rhizosphere inoculum, according to a $t$ test. Error bars represent $\pm \mathrm{SE}(n=5)$.

bands was performed in reference to a hypothetical composite lane containing bands at all positions found across the entire data set. Binomial band-matching data were exported using Excel (Microsoft Corporation, Redmond, Washington, USA) for statistical analysis. In the statistical analysis, we performed the tests with and without the samples that did not have any AMF band, in order to examine consequences of band absences due to PCR bias for the outcome of analyses. As both approaches showed only minor statistical and graphical differences, we present the analysis of the full database, assuming that band absences indicate the presence of AMF under the detection level, or AMF that could not be picked up by the primers we used. Effects of plant species identity on AMF composition were tested using canonical correspondence analysis (CCA) with Monte Carlo permutation tests (499 unrestricted permutations). CCA was performed using CANOCO for Windows 4.5 (Ter Braak and Šmilauer 2002). As permutation tests showed that AMF banding patterns did not differ significantly between roots from the field and the pot experiment $(P>0.05)$, we used both field and pot data for comparing AMF banding patterns of the three plant species. The eigenvalues, $F$, and $P$ values of the second axis were calculated using the sample scores of the first axis as covariate.

\section{RESULTS}

\section{Soil conditioning and feedback experiments}

In the soil conditioning stage, the addition of conspecific rhizosphere soil-enhanced shoot biomass of the exotic grass $C$. biflorus $\left(t_{8}=-2.832 ; P<0.05\right)$, whereas addition of conspecific rhizosphere soil had a neutral effect on shoot biomass of the two native grasses ( $t_{8}=-1.209$ for E. lehmanniana and $t_{8}=-1.601$ for $A$. meridionalis; $P>0.05$; Fig. 1). In the feedback experiment with nonsterilized and sterilized conspecific soil that had been inoculated prior to the conditioning stage, the exotic $C$. biflorus had a neutral $\left(t_{4}=0.09, P=\right.$ 0.93 ) and the two native grasses a significantly negative soil feedback ( $A$. meridionalis, $t_{1}=-18.90, P=0.034 ; E$. lehmanniana, $\left.t_{4}=-4.38, P=0.011\right)$. There was also a significant difference in performance among the three grasses $\left(F_{2,9}=10.7, P<0.01\right)$. The soil feedbacks of the two native grasses were not significantly different from each other, whereas these were significantly stronger (negative) than for the exotic $C$. biflorus $(P<0.05$; Fig. 2).

The use of sterilized soil in analyzing soil feedback effects involves an effect of soil biota, as well as an effect of nutrient mobilization due to the sterilization procedure. Therefore, we also compared the feedback effect of conspecifics between soil with and without rhizosphere addition (cross-hatched in Fig. 3). Interestingly, here in conspecific soil, A. meridionalis and E. lehmanniana both had neutral feedback effects $\left(t_{1}=-0.90, P=0.533\right.$ and $t_{4}$ $=-0.817, P=0.460$, respectively), while the exotic $C$. biflorus had significantly positive feedback $\left(t_{4}=6.94, P=\right.$ 0.002). In heterospecific soil from the other native grass, A. meridionalis was not significantly influenced $\left(t_{2}=\right.$ 3.43, $P=0.076$ ), while $E$. lehmanniana had negative feedback $\left(t_{4}=-4.24, P=0.013\right.$; vertically hatched in Fig. 3). In heterospecific soil from the exotic C. biflorus, A. meridionalis had a significantly positive feedback effect ( $\left.t_{3}=7.96, P=0.004\right)$, while the feedback effect of E. lehmanniana was not significantly different from zero $\left(t_{4}=0.67, P=0.539\right)$. Interestingly, the exotic $C$. biflorus had a neutral soil feedback effect from $A$. meridionalis $\left(t_{4}=-0.20, P=0.851\right)$, and a positive feedback effect from $E$. lehmanniana $\left(t_{4}=3.29, P=0.030\right.$; horizontally hatched in Fig. 3). Therefore, in this trial both the exotic

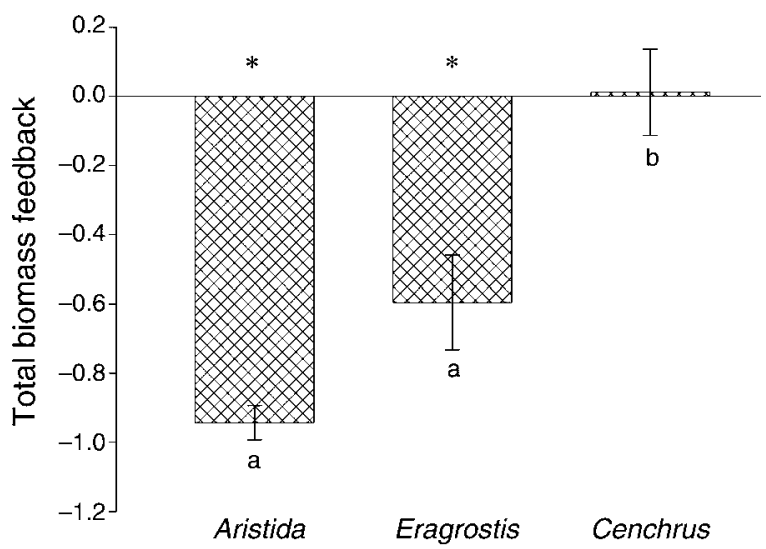

FIG. 2. The soil feedback experiment uses a comparison between sterilized and nonsterilized soil ([biomass in nonsterilized - biomass in sterilized soil]/biomass in sterilized soil) for Aristida meridionalis, Cenchrus biflorus, and Eragrostis lehmanniana. Significant differences $(P<0.05)$ between plant species are indicated by different lowercase letters; significant differences (after a $t$ test) of each of the bars from zero are indicated with asterisks $\left({ }^{*} P<0.05\right)$. 

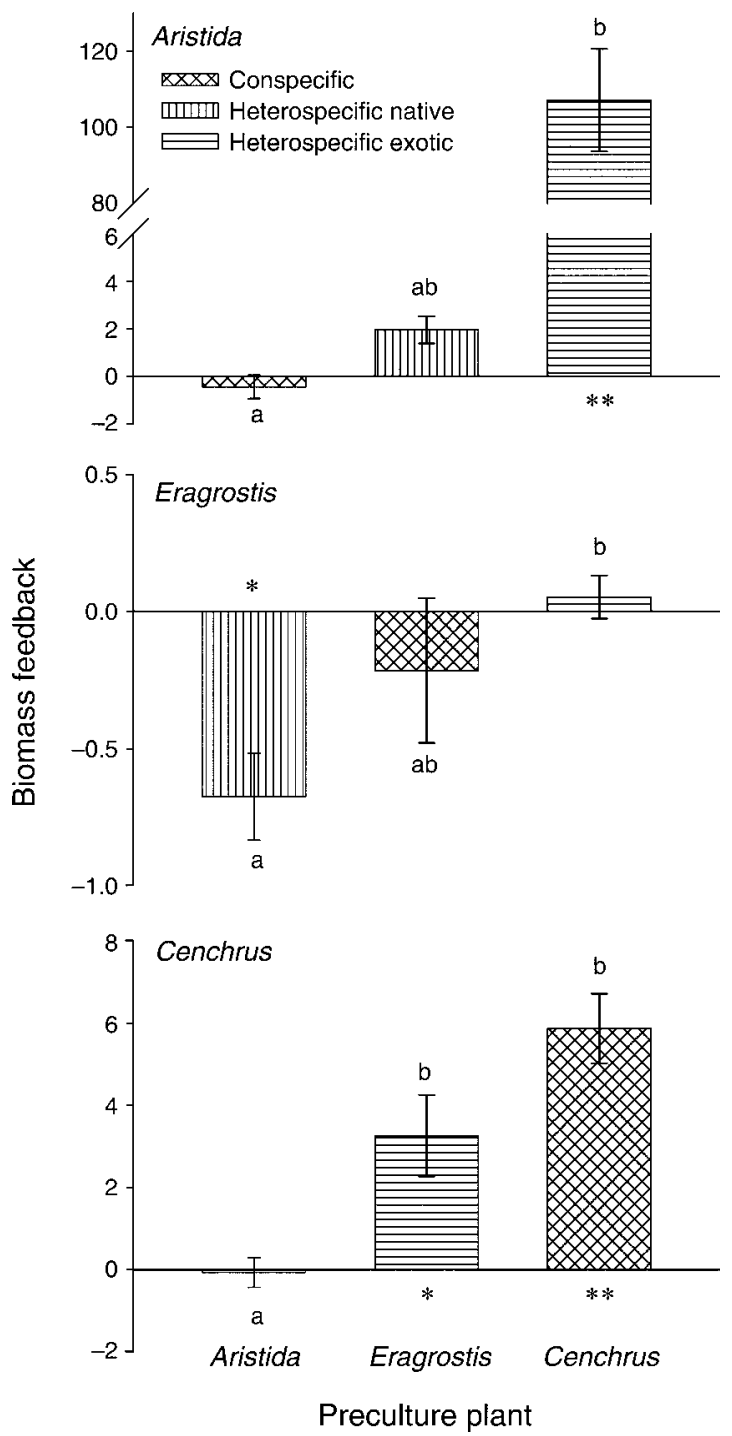

FIG. 3. The feedback experiment uses a comparison of soil conditioned with and without $3 \%$ rhizosphere inoculum. The soil feedback has been calculated as (biomass in inoculated soil - biomass in noninoculated soil)/biomass in noninoculated soil. Feedback effects of Cenchrus, Eragrostis, and Aristida are presented in their own (conspecific) soil and in soil of other (heterospecific) species. Significant differences $(P<0.05)$ between plant species are indicated by different lowercase letters, while significant differences of each of the bars from zero (after a $t$ test) are indicated with asterisks $\left(* P<0.05 ;{ }^{*} P\right.$ $<0.01)$.

C. biflorus and the native A. meridionalis had neutral to positive feedback, whereas the native E. lehmanniana had negative soil feedback.

\section{Fungal pathogenicity tests}

The first two trials with fungi collected from the plant roots in the soil conditioning phase were carried out with E. lehmanniana, because that species was the only one to show a negative trend in response to conditioning with rhizosphere inoculum (Fig. 1). These roots had also been stained, and they were well colonized with AMF (data not shown). In the first fungal inoculum trial, when four inocula were tested and compared with a control by ANOVA, there was a significant effect of inoculum $\left(P<0.001, F_{4,38}=11.080\right)$, time $(P<0.001$, $\left.F_{6,228}=23184\right)$, and inoculum $\times$ time $\left(P<0.001, F_{24,228}\right.$ $=3142)$. The effect of the fungus E1 on E. lehmanniana increased with time, while all other fungi, including those isolated from $C$. biflorus, had no effect when compared to the control (Fig. 4a). The first experiment was terminated after 24 days, because of the lack of additional necrosis formation during days 17-24 of the experiment. The second trial also resulted in a significant effect of inoculum $\times$ time $\left(F_{30,270}=3.628 ; P<0.001\right)$, while main effects were also significant for inoculum $\left(F_{5,45}=9.199 ; P<0.001\right)$, as well as for time $\left(F_{6,270}=\right.$ 24.055; $P<0.001)$. From day 25 onwards, the fungus E11 caused more necrosis to E. lehmanniana than the control (Fig. 4b). The second experiment was carried on

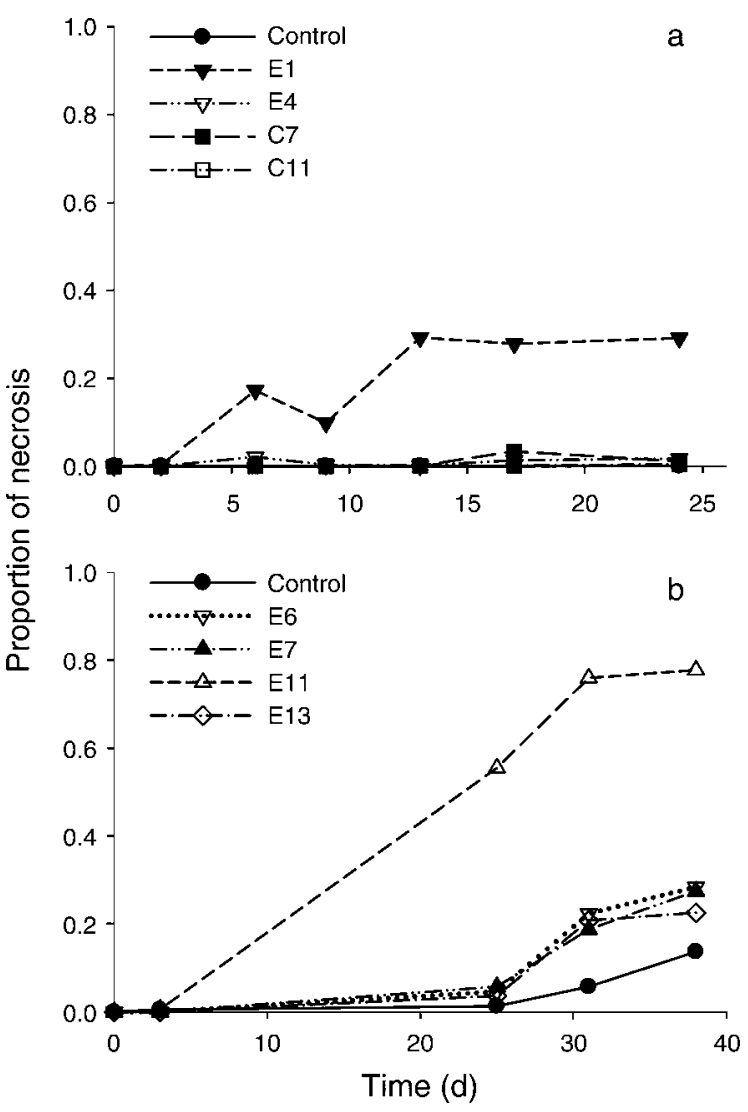

FIG. 4. The proportion of leaf necrosis of Eragrostis lehmanniana leaves in two inoculation trials: (a) with dominant fungi from its own roots and from roots of the exotic species Cenchrus biflorus, and (b) with dominant fungi from its own roots only. The fungi have been coded by a letter (E, Eragrostis; $\mathrm{C}$, Cenchrus) and the number of the isolate. The fungus E1 has been identified as Fusarium avenaceum Saccardo, and the fungus E11 as an ascomycete. Back-transformed data were used to conform with statistical analyses. 


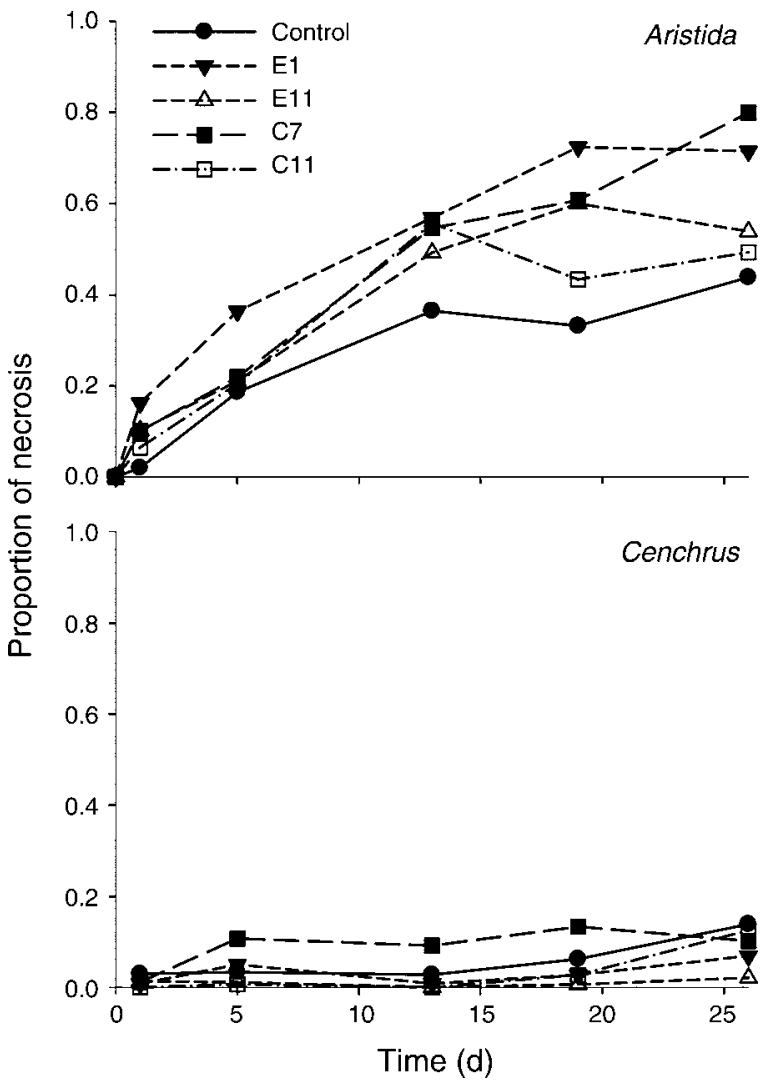

FIG. 5. The proportion of leaf necrosis for the native grass Aristida meridionalis and back-transformed data of the exotic Cenchrus biflorus with dominant fungi from the native grass Eragrostis lehmanniana and the exotic grass C. biflorus. See Fig. 4 for fungi codes.

for 38 days, in order to compare the effectiveness of E11 for a longer period, and it appeared that the statistical difference between E11 and the other fungi disappeared with time. These two inoculation experiments showed that two of the dominant fungal species isolated from inside the roots of E. lehmanniana were pathogenic to this host plant. The two dominant fungal species isolated from the invader C. biflorus, on the other hand, were not pathogenic to E. lehmanniana, which corresponds with a neutral feedback effect of E. lehmanniana on soil conditioned by $C$. biflorus. The fungus E1 has been identified as Fusarium avenaceum Saccardo and the fungus E11 was identified as an ascomycete, but further morphological identification was not possible because this strain was nonsporulating.

In the third trial, we tested the fungi E1 ( $F$. avenaceum) and E11 (the ascomycete), C7 and C11 on A. meridionalis and C. biflorus (Fig. 5). Effects of the fungi on leaf necrosis of $A$. meridionalis depended on time $\left(F_{4,104}=41.184 ; P<0.001\right)$. During the first 13 days, the percentage of necrosis increased, after which it stabilized. There was, however, no significant difference between necrosis of $A$. meridionalis in the fungal treatments and the control, so that $A$. meridionalis was not influenced by fungi from $E$. lehmanniana and $C$. biflorus. The effects of the fungi on necrosis of $C$. biflorus depended on inoculum $\left(F_{4,45}=2.752 ; P<0.05\right)$ and time $\left(F_{4,180}=8.976 ; P<0.001\right)$. The inoculum effect was due to more necrosis with $\mathrm{C} 7$ from $C$. biflorus than with $\mathrm{E} 11$ from E. lehmanniana. However, as there were no differences $(P>0.05)$ between individual fungi and the control, the fungal inoculum effect of $C$. biflorus may not necessarily be due to a pathogenic effect.

\section{Molecular analysis and CCA of AMF in roots}

Visual inspection of stained roots confirmed that AMF were present in all three plant species in the inoculated (and nonsterilized) soil from the conditioning and feedback experiments, as well as in the roots from field and pot soil used for molecular AMF identification (data not shown). PCR products of the expected size ( $\sim 550$ base pairs [bp]) could be obtained from most field and experimental root samples, and these products have been examined using the AMF-specific NS31-GC/AM1 primer pair; 17/21 and 26/30, respectively. All samples yielded PCR products when tested with general fungal PCR primers, indicating that the few negative results may have been the result of AMF template concentrations below the limit of detection, primer inefficiencies, or PCR inhibition. As PCR-bias could not be excluded, the two samples without bands were excluded from DGGE analysis. DGGE analysis of AMF-specific PCR products yielded between one and six detectable bands per root sample analyzed, and a total of 20 different band positions were discriminated across the entire data set of which 14 positions represented AMF (see Appendix B).

There were no significant differences in AMF banding patterns between plant roots from field and pot experiments $(P>0.05$; permutation test data not shown). Therefore, in the final analysis we have included all data from field and pots. The first canonical axis (eigenvalue $0.513, F=3.786, P=0.002$ ) mainly separated the two native grasses, and this axis explained $9.8 \%$ of the variance (Fig. 6). Excluding samples that generated DNA, but no bands in the DGGE, had only minor effects on statistics (eigenvalue 0.474, $F=4.139, P=$ 0.002 ) or graphical presentation (data not shown), so that we only present the full analysis, including samples with no bands in the DGGE. The second canonical axis mainly distinguished between native and exotic grasses and explained $7.2 \%$ of the variance (eigenvalue $0.383, F$ $=3.073, P=0.002$ ), so that native grasses differ as much from each other as the native and exotic species (Fig. 6). Some DGGE bands were unevenly distributed across the different plant species, with two bands appearing to be distinctly associated with $C$. biflorus (bands 4 and 5 in Fig. 6). These two DGGE bands, which always appeared together when detected in this plant species, were present in $>73 \%$ of the $C$. biflorus root samples examined (Appendix B). Band excision and subsequent sequence analysis revealed that these bands represented 


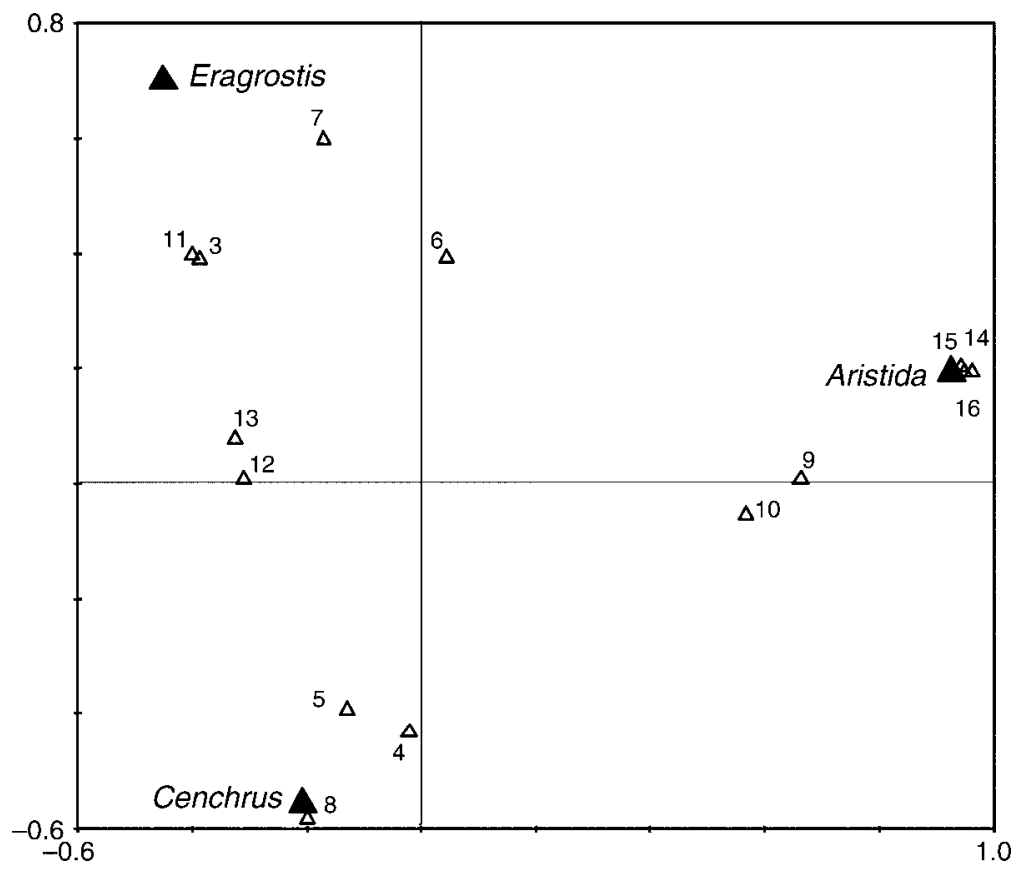

FIG. 6. Canonical correspondence analysis (CCA) biplot of the arbuscular mycorrhizal fungi banding patterns (indicated as absence or presence) in roots of the native Kalahari savanna grasses E. lehmanniana and $A$. meridionalis and of the exotic grass $C$. biflorus. The root samples originated from the field, as well as from a pot experiment with plants individually grown in field soil. Data from field and pot could not be discriminated $(P>0.05)$, so that the CCA presented has been based on all samples. Bands 4 and 5 , which occurred in $73 \%$ of all root samples of C. biflorus, were $99 \%$ similar to Glomus versiforme. Band 8 occurred in only one sample. Overlapping data points have been offset.

nearly identical sequences, differing by only one base pair. Their sequences showed $>99 \%$ identity to the $18 \mathrm{~S}$ rDNA sequence reported for Glomus versiforme (accession no. X86687). Band 8 was also associated with $C$. biflorus; however, this band was detected in only one sample (Appendix B). Overall, the CCA analysis showed that the exotic $C$. biflorus was associated with two dominant DGGE bands (4 and 5, see Fig. 6), which occurred in $73 \%$ of the field and pot experiment samples. One AMF band (8) occurred in $<10 \%$ of the field and pot experiment samples. The native grasses $A$. meridionalis and E. lehmanniana were associated with 4-6 AMF sequences each, without a prominent contribution of $G$. versiforme, and the percentage infected appeared lower than that of $C$. biflorus (data not shown).

\section{DisCUSSION}

Our results show that the soil community exerted neutral to positive feedback on the exotic grass $C$. biflorus and neutral to negative feedback on the native grasses A. meridionalis and E. lehmanniana. We assessed plant soil feedback in two ways, because of possible shortcomings of the different methods. Comparing biomass production in sterilized and nonsterilized soils that had been inoculated prior to soil conditioning may have resulted in nutrient flushes, thereby enhancing the amount of available nitrogen and phosphate in the sterilized soil (Troelstra et al. 2001). To avoid differences in nutrient availabilities in the sterilized and nonsterilized soils, nutrients were supplied. The results of this feedback experiment suggested net negative effects of the soil community (among which are pathogens and AMF) on the native grasses, and a net neutral effect of the soil community on the exotic grass. However, the nutrients supplied may have led to an underestimation of AMF effects due to reduced root infection or reduced mycorrhizal effectiveness (Kardol et al. 2006).

As an alternative approach, we compared the feedback in soils that had been inoculated or not inoculated with $3 \%$ field soil prior to the conditioning phase. This procedure, although sensitive for stochastic colonization of the noninoculated sterilized soil during the conditioning phase, generated a feedback difference between the native and the exotic grasses similar to the sterilized and nonsterilized soil comparison. The natives had a neutral and the exotic grass had a positive soil feedback, suggesting net neutral effects of pathogens and $\mathrm{AMF}$ in the native grasses and a net positive effect of AMF in the exotic grass. Therefore, the two feedback trials differed in assessing the proportional role of negative vs. positive soilborne growth-influencing factors; however, they consistently showed that the exotic C. biflorus had a more positive soil feedback than both native grasses. This conclusion is also supported by biomass differences in the conditioning stage, where a $3 \%$ rhizosphere soil inoculum significantly enhanced 
shoot biomass production of the exotic grass, while soil inoculation did not have a significant influence on shoot biomass of either native grass.

Whereas the comparison between sterilized and nonsterilized soil suggested enemy release (Keane and Crawley 2002), the comparison between inoculated and noninoculated soil suggested enhanced benefit of the exotic grass from mutualistic symbionts (Richardson et al. 2000). In order to further elucidate the possible role of soil pathogens, we examined fungi from the roots (where most pathogens are localized) of the native plant that showed the strongest tendency to respond in the soil-conditioning stage (E. lehmanniana), as well as fungi from the roots of the exotic $C$. biflorus. Interestingly, the roots of the native E. lehmanniana harbored two fungi, Fusarium avenaceum Saccardo and an ascomycete, that caused pathogenic effects to their host, but not to the exotic grass or to the other native grass $A$. meridionalis. In contrast, the dominant fungi collected from the exotic grass $C$. biflorus did not exert any pathogenic activity to the native grasses E. lehmanniana and $A$. meridionalis. These results support the possibility that a host-specific soil pathogen has contributed to the negative feedback effect of E. lehmanniana in the experiment with sterilized and nonsterilized inoculated (conditioned) soil. This finding is of interest, because $E$. lehmanniana is a notorious invader in the southern United States (Kincaid et al. 1959), in which absence of natural soilborne enemies could also play a role. The rootinhabiting fungi isolated from the exotic C. biflorus were not pathogenic to their host, supporting the hypothesis of enemy release. However, we do not have information on natural enemies of $C$. biflorus in its native range, which is essential for a better conclusion about enemy release (Hierro et al. 2005).

Further studies also need to isolate fungi from the roots of $A$. meridionalis. This native grass did not respond negatively to fungi isolated from E. lehmanniana and $C$. biflorus, which was in line with the feedback effects in the heterospecifically conditioned soils. $E$. lehmanniana showed a negative response to soil conditioned by $A$. meridionalis, and further pathogen trials are needed to determine if $A$. meridionalis hosts pathogens that are negatively influencing the other native grass, $E$. lehmanniana. Such one-sided pathogenic effects may influence plant community dynamics, such as succession in plant communities (Van der Putten et al. 1993). As the fungi on the roots of $C$. biflorus did not negatively influence the two native grasses, we did not find support for the hypothesis regarding the accumulation of local pathogens (Eppinga et al. 2006).

The detection of two DGGE bands in the majority of C. biflorus samples suggests a high degree of selectivity with respect to AMF infection of the exotic plant species. In contrast to the low diversity of AMF banding patterns on $C$. biflorus, both native grasses had 4-6 $\mathrm{AMF}$ sequences; however, these sequences were far less frequently present among replicate samples. This was observed for plants collected from various field locations, as well as those grown in the mixed-soil experiment, which contained the full diversity of AMF inoculum from soils of different plant species. Whether the observed pattern for the exotic grass is due to selectivity of the local AMF, to inability of C. biflorus to associate with local AMF, or to other factors (e.g., interspecific competition among AMF) cannot be concluded. However, our results strongly suggest that if exotic plants may get access to local mutualists (Richardson et al. 2000), they could change local AMF community structure due to selective effects. Previous studies have shown that invasive grassland plants had higher levels of AMF (Batten 2006), and that invasive plants did not have any negative effect on total spore density and $\alpha$-diversity of mycorrhizal spore communities in dry tropical forests (Johnson and Wedin 1997). Follow-up studies are needed to determine the functional consequences of these differences in AMF diversity for both the native and exotic grasses, as the functioning of AMF can be strongly environmentally dependent (Johnson et al. 1997).

The sequences recovered from the two bands in the roots of $C$. biflorus were nearly identical to each other, differing by only a single base pair. When present in $C$. biflorus, they always co-occurred, suggesting a probable origin from a single AMF population, given the demonstrated heterogeneity of rRNA operons within single AMF individuals (Clapp et al. 1999). Different AMF species may overlap in their phylogenies, and individual species may possess several rDNA lineages (de Souza et al. 2004). Thus, despite the $>99 \%$ sequence identity between these two bands reported for Glomus versiforme (accession no. X86687), it would be premature to conclude that they indeed represent this species. Finally, the NS31/AM1 primer pair fails to target some members of the Glomeromycota, most notably the Archaeosporales and Paraglomerales, and our analysis will therefore not include members of these orders, while they may amplify $18 \mathrm{~S}$ rDNA sequences from non-AMF sources in some cases (Ma et al. 2005). Our results are, therefore, limited to the primer sets used. The data strongly suggest that there are fewer associations of the exotic $C$. biflorus with local AMF taxa than the two native grasses, without any deleterious effect on performance of the native plants in soils conditioned by the exotic species. These results are opposite to findings in North American forests (Stinson et al. 2006).

In conclusion, our results show that the high local abundance of the exotic $C$. biflorus in the Kalahari savanna was correlated with neutral to positive feedback with the soil community, while the two native grasses had neutral to negative soil feedback. Isolation and testing of root-inhabiting soil fungi showed that the native grass E. lehmanniana contained some pathogenic fungi, which were not pathogenic to the exotic grass, but also not to the other native grass, A. meridionalis. The 
exotic grass was well colonized with AMF, but the diversity of the mycorrhizal community was considerably lower (probably mainly one single AMF species) than for the two native grasses, indicating shifts in fungal community composition due to the invasive grass (Hawkes et al. 2006). Our results are not in support of the view that, from a mycorrhizal diversity perspective, exotic plants may get easy access to local arbuscular mycorrhizal fungi in their new range, but our results leave open the possibility that interactions between the exotic plant species and some local AMF can be highly effective. The plant-soil interactions may contribute to the observed high local abundance of the exotic grass; however, other factors, such as vector-mediated dispersal, will be crucial for the rapid spread, which is another major feature of plant invasiveness (Levine et al. 2006).

\section{ACKNOWLEDGMENTS}

This study was carried out as part of the project on invasive grasses in coastal and inland dunes in Southern Africa (INVASS), subsidized by the European Commission INCODC program (contract IC18CT971045), and an ALW-VICI grant to W. H. van der Putten. We thank Paul Kardol for help with CANOCO analysis and his valuable suggestions to improve the manuscript. This is Publication 3955 of the Netherlands Institute of Ecology (NIOO-KNAW).

\section{Literature Cited}

Agrawal, A. A., P. M. Kotanen, C. E. Mitchell, A. G. Power, W. Godsoe, and J. Klironomos. 2005. Enemy release? An experiment with congeneric plant pairs and diverse aboveand belowground enemies. Ecology 86:2979-2989.

Altschul, S. F., T. L. Madden, A. A. Schaffer, J. H. Zhang, Z. Zhang, W. Miller, and D. J. Lipman. 1997. Gapped BLAST and PSI-BLAST: a new generation of protein database search programs. Nucleic Acids Research 25:3389-3402.

Anable, M. E., M. P. McClaran, and G. B. Ruyle. 1992. Spread of introduced Lehmann lovegrass Eragrostis lehmanniana Nees in Southern Arizona, USA. Biological Conservation 61: 181-188.

Anonymous. 1996. Lost crops of Africa. National Research Council (Washington). Board on Science and Technology for International Development, National Academic Press, Washington, D.C., USA.

Batten, K. M., K. M. Scow, K. F. Davies, and S. P. Harrison. 2006. Two invasive plants alter soil microbial community composition in serpentine grasslands. Biological Invasions 8: 217-230.

Beckstead, J., and I. M. Parker. 2003. Invasiveness of Ammophila arenaria: Release from soil-borne pathogens? Ecology 84:2824-2831.

Bever, J. D., K. M. Westover, and J. Antonovics. 1997. Incorporating the soil community into plant population dynamics: the utility of the feedback approach. Journal of Ecology 85:561-573.

Bond, J. M., E. M. Veenendaal, D. D. Hornby, and J. A. Gray. 2002. Looking for progenitors: a molecular approach to finding the origins of an invasive weed. Biological Invasions 4:349-357.

Callaway, R. M., G. C. Thelen, S. Barth, P. W. Ramsey, and J. E. Gannon. 2004. Soil fungi alter interactions between the invader Centaurea maculosa and North American natives. Ecology 85:1062-1071.

Clapp, J. P., A. H. Fitter, and J. P. W. Young. 1999. Ribosomal small subunit sequence variation within spores of an arbuscular mycorrhizal fungus, Scutellospora sp. Molecular Ecology 8:915-921.
Colautti, R. I., A. Ricciardi, I. A. Grigorovich, and H. J. MacIsaac. 2004. Is invasion success explained by the enemy release hypothesis? Ecology Letters 7:721-733.

Cox, J. R., G. B. Ruyle, and B. A. Roundy. 1990. Lehmann lovegrass in southeastern Arizona-biomass production and disappearance. Journal of Range Management 43:367-372.

De Rooij-van der Goes, P. C. E. M. 1995. The role of plantparasitic nematodes and soil-borne fungi in the decline of Ammophila arenaria (L.) Link. New Phytologist 129:661-669.

de Souza, F. A., G. A. Kowalchuk, P. Leeflang, J. A. van Veen, and E. Smit. 2004. PCR-denaturing gradient gel electrophoresis profiling of inter- and intraspecies 18S rRNA gene sequence heterogeneity is an accurate and sensitive method to assess species diversity of arbuscular mycorrhizal fungi of the genus Gigaspora. Applied and Environmental Microbiology 70:1413-1424.

Eppinga, M. B., M. Rietkerk, S. C. Dekker, P. C. De Ruiter, and W. H. Van der Putten. 2006. Accumulation of local pathogens: a new hypothesis to explain exotic plant invasions. Oikos 114:168-176.

Gibbs Russel, G. E., L. Watson, M. Koekemoer, L. Smook, N. P. Barker, H. M. Anderson, and M. J. Dallwitz. 1991. Grasses of southern Africa. National Botanical Institute, Pretoria, South Africa.

Hawkes, C. V., J. Belnap, C. D'Antonio, and M. K. Firestone. 2006. Arbuscular mycorrhizal assemblages in native plant roots change in the presence of invasive exotic grasses. Plant and Soil 281:369-380.

Helgason, T., T. J. Daniell, R. Husband, A. H. Fitter, and J. P. W. Young. 1998. Ploughing up the wood-wide web? Nature 394:431.

Hierro, J. L., J. L. Maron, and R. M. Callaway. 2005. A biogeographical approach to plant invasions: the importance of studying exotics in their introduced and native range. Journal of Ecology 93:5-15.

Jobin, A., U. Schaffner, and W. Nentwig. 1996. The structure of the phytophagous insect fauna on the introduced weed Solidago altissima in Switzerland. Entomologia Experimentalis et Applicata 79:33-42.

Johnson, N. C., J. H. Graham, and F. A. Smith. 1997. Functioning of mycorrhizal associations along the mutualism-parasitism continuum. New Phytologist 135:575-586.

Johnson, N. C., and D. A. Wedin. 1997. Soil carbon, nutrients, and mycorrhizae during conversion of dry tropical forest to grassland. Ecological Applications 7:171-182.

Kardol, P., T. M. Bezemer, and W. H. Van der Putten. 2006. Temporal variation in plant-soil feedback controls succession. Ecology Letters 9:1080-1088.

Keane, R. M., and M. J. Crawley. 2002. Exotic plant invasions and the enemy release hypothesis. Trends in Ecology and Evolution 17:164-170.

Kincaid, D. R., G. A. Holt, P. D. Dalton, and J. S. Tixier. 1959. The spread of Lehmann lovegrass as affected by mesquite and native perennial grasses. Ecology 40:738-742.

Klironomos, J. N. 2002. Feedback with soil biota contributes to plant rarity and invasiveness in communities. Nature 417:6770.

Knevel, I. C., T. Lans, F. B. J. Menting, U. M. Hertling, and W. H. van der Putten. 2004. Release from native root herbivores and biotic resistance by soil pathogens in a new habitat both affect the alien Ammophila arenaria in South Africa. Oecologia 141:502-510.

Kowalchuk, G. A., S. Gerards, and J. W. Woldendorp. 1997. Detection and characterization of fungal infections of Ammophila arenaria (marram grass) roots by denaturing gradient gel electrophoresis of specifically amplified $18 \mathrm{~S}$ rDNA. Applied and Environmental Microbiology 63:38583865.

Levine, J. M., E. Pachepsky, B. E. Kendall, S. G. Yelenik, and J. H. R. Lambers. 2006. Plant-soil feedbacks and invasive spread. Ecology Letters 9:1005-1014. 
Ma, W. K., S. D. Siciliano, and J. J. Germida. 2005. A PCR DGGE method for detecting arbuscular mycorrhizal fungi in cultivated soils. Soil Biology and Biochemistry 37:1589-1597.

Marler, M. J., C. A. Zabinski, and R. M. Callaway. 1999. Mycorrhizae indirectly enhance competitive effects of an invasive forb on a native bunchgrass. Ecology 80:1180-1186.

Memmott, J., S. V. Fowler, Q. Paynter, A. W. Sheppard, and P. Syrett. 2000. The invertebrate fauna on broom, Cytisus scoparius, in two native and two exotic habitats. Acta Oecologica-International Journal of Ecology 21:213-222.

Mitchell, C. E., and A. G. Power. 2003. Release of invasive plants from fungal and viral pathogens. Nature 421:625-627.

Müller-Schärer, H., U. Schaffner, and T. Steinger. 2004. Evolution in invasive plants: implications for biological control. Trends in Ecology and Evolution 19:417-422.

Mummey, D. L., M. C. Rillig, and W. E. Holben. 2005. Neighboring plant influences on arbuscular mycorrhizal fungal community composition as assessed by T-RFLP analysis. Plant and Soil 271:83-90.

Muyzer, G., T. Brinkhoff, U. Nübel, C. Santegoeds, H. Shäfer, and C. Wawer. 1998. Denaturing gradient gel electrophoresis (DGGE) in microbial ecology. Pages $1-27$ in A. D. L. Akkermans, J. D. van Elsas, and F. J. de Bruijn, editors. Molecular microbial ecology manual. Kluwer Academic, Dordrecht, The Netherlands.

Parker, J. D., D. E. Burkepile, and M. E. Hay. 2006. Opposing effects of native and exotic herbivores on plant invasions. Science 311:1459-1461.

Parker, J. D., and M. E. Hay. 2005. Biotic resistance to plant invasions? Native herbivores prefer non-native plants. Ecology Letters 8:959-967.

Reinhart, K. O., and R. M. Callaway. 2004. Soil biota facilitate exotic Acer invasions in Europe and North America. Ecological Applications 14:1737-1745.

Reinhart, K. O., and R. M. Callaway. 2006. Soil biota and invasive plants. New Phytologist 170:445-457.

Reinhart, K. O., A. Packer, W. H. Van der Putten, and K. Clay. 2003. Plant-soil biota interactions and spatial distribution of black cherry in its native and invasive ranges. Ecology Letters 6:1046-1050

Richardson, D. M., N. Allsopp, C. M. D’Antonio, S. J. Milton, and M. Rejmanek. 2000. Plant invasions - the role of mutualisms. Biological Reviews 75:65-93.

Simon, L., M. Lalonde, and T. D. Bruns. 1992. Specific amplification of $18 \mathrm{~S}$ fungal ribosomal genes from vesiculararbuscular endomycorrhizal fungi colonizing roots. Applied and Environmental Microbiology 58:291-295.

Stinson, K. A., S. A. Campbell, J. R. Powell, B. E. Wolfe, R. M. Callaway, G. C. Thelen, S. G. Hallett, D. Prati, and J. N. Klironomos. 2006. Invasive plant suppresses the growth of native tree seedlings by disrupting belowground mutualisms. PLOS Biology 4:727-731.

Ter Braak, C. J. F., and P. Šmilauer. 2002. CANOCO for Windows 4.5. Biometris, Wageningen-UR, Wageningen, The Netherlands.

Troelstra, S. R., R. Wagenaar, W. Smant, and B. A. M. Peters. 2001. Interpretation of bioassays in the study of interactions between soil organisms and plants: involvement of nutrient factors. New Phytologist 150:697-706.

Van der Putten, W. H. 2003. Plant defense belowground and spatiotemporal processes in natural vegetation. Ecology 84: 2269-2280.

Van der Putten, W. H., C. Van Dijk, and B. A. M. Peters. 1993. Plant-specific soil-borne diseases contribute to succession in foredune vegetation. Nature 362:53-56.

Van der Putten, W. H., C. Van Dijk, and S. R. Troelstra. 1988. Biotic soil factors affecting the growth and development of Ammophila arenaria. Oecologia 76:313-320.

Wardle, D. A., R. D. Bardgett, J. N. Klironomos, H. Setälä, W. H. Van der Putten, and D. H. Wall. 2004. Ecological linkages between aboveground and belowground biota. Science 304:1629-1633.

Williamson, M. 1996. Biological invasions. Chapman and Hall, London, UK.

\section{APPENDIX A}

Methods used for DNA isolation, PCR amplifications, and DGGE analysis of arbuscular mycorrhizal fungi (Ecological Archives E088-061-A1).

\section{APPENDIX B}

A table showing positions of 14 bands (representing arbuscular mycorrhizal fungi taxa) obtained by PCR-DGGE with mycorrhiza-specific primers (Ecological Archives E088-061-A2). 